\title{
PET Imaging in Differentiated Thyroid Cancer: Where Does It Fit and How Do We Use It?
}

\begin{abstract}
Positron emission tomography (PET) is a rapidly evolving imaging modality that has gained widespread acceptance in oncology, with several radionuclides applicable to thyroid cancer. Thyroid cancer patients have been studied most commonly using ${ }^{18}$ F-Fluorodeoxyglucose (FDG)-PET, with perhaps the greatest utility being the potential localization of tumor in differentiated thyroid cancer (DTC) patients who are radioiodine whole body scan (WBS) negative and thyroglobulin $(\mathrm{Tg})$ positive. Also of value is the identification of patients unlikely to benefit from additional 131 | therapy and identification of patients at highest risk of disease-specific mortality, which may prompt more aggressive therapy or enrollment in clinical trials. Emerging data suggest that PET/CT fusion studies provide increased accuracy and modify the treatment plan in a significant number of DTC cases when compared to PET images alone. However, studies documenting improvements in survival and tumor recurrence attributable to FDG-PET imaging in thyroid cancer patients are lacking. Specific case examples of thyroid cancer patients who appear to have benefited from FDG-PET imaging do exist, while less data are available in the setting of anaplastic or medullary thyroid carcinoma. This article reviews the utility and limitations of FDG-PET in DTC management, and offers practical recommendations. (Arq Bras Endocrinol Metab 2007;51/5:793-805)
\end{abstract}

Keywords: Fluorodeoxyglucose ${ }^{18} \mathrm{~F}$; Positron-emission tomography; Thyroid cancer; Follicular carcinoma; Thyroid nodules; Thyroid

\section{RESUMO}

Imagem por PET no Câncer Diferenciado de Tiróide: Onde Ele se Encaixa e Como Usá-lo?

Positron emission tomography (PET) é uma modalidade de imagem que vem evoluindo rapidamente e tem ganho ampla aceitação na oncologia em geral e no câncer da tiróide em particular, graças a uma série de radionuclídeos. Pacientes com doenças da tiróide têm sido estudados principalmente com ${ }^{18} \mathrm{~F}$ Fluorodeoxiglicose (FDG)-PET, cuja maior utilidade talvez seja a de poder localizar tumor em pacientes negativos na pesquisa de corpo inteiro e com tireoglobulina positiva. Também é útil na identificação de pacientes que não devem se beneficiar de terapia adicional com ${ }^{131} \mathrm{I}$ e de pacientes de alto risco que podem se beneficiar de terapias mais agressivas ou testes clínicos com drogas alvo-dirigidas. Dados recentes sugerem que a fusão $\mathrm{PET} / \mathrm{CT}$ aumenta a acurácia e modifica o plano terapêutico de um número significativo de casos de CDT comparada com as imagens de PET apenas. Entretanto, ainda não existem estudos que documentem melhora na sobrevida e na recorrência decorrentes da imagem por FDG-PET em pacientes com câncer da tiróide. Existem exemplos específicos de casos de CDT que aparentemente se beneficiaram do FDG-PET, mas há menos dados relativos ao carcinoma anaplásico ou ao medular. Este artigo revê a utilidade e as limitações do FDG-PET no tratamento do CDT e oferece recomendações práticas. (Arq Bras Endocrinol Metab 2007;51/5:793-805)

Descritores: Fluorodeoxiglicose 18F; Positron-emission tomography (PET); Câncer da tiróide; Carcinoma folicular; Nódulos da tiróide; Tiróide

\section{revisão}

\author{
NATHAN C. HALL \\ RICHARD T. KLOOS
}

Division of Nuclear Medicine

$(\mathrm{NCH})$, and Divisions of

Endocrinology, Diabetes and Metabolism \& Nuclear Medicine (RTK), The Ohio State University, The Arthur $G$. James Cancer Hospital and Richard J. Solove Research Center, and The Ohio State University Comprehensive Cancer Center, Columbus, Ohio, USA.

Recebido em 05/03/07

Aceito em 16/04/07 
P OSITRON EMISSION TOMOGRAPHY (PET) is an increasingly utilized imaging modality for oncology. Nuclear medicine has been re-invigorated with this new technology, and PET has reminded radiologists that molecular imaging is important. Indeed, use of FDGPET for cancer screening among the asymptomatic population is not uncommon, with discovery of unsuspected malignancy in up to $3.2 \%$ (1). Nearly all manufacturers of nuclear medicine equipment are focused in PET technology; advancing image quality, resolution, speed, and fusion with CT images. Instrumentation features and advertising that appeal to patients, including "open" imaging systems, are beginning to emerge in an increasingly competitive market. Meanwhile, experts have cautioned that the new dual-modality PET/CT has become readily accepted in practice despite often limited experience and sparse but growing evidence of true effectiveness (2).

\section{WHAT IS POSITRON EMISSION TOMOGRAPHY (PET)?}

PET utilizes a ring detector system for coincidence detections of $511 \mathrm{keV}$ photons emitted from positron emitting radionuclides. Images are then reconstructed in three dimensions using reconstruction algorithms, with or without attenuation correction. The most common positron-emitting radioisotopes applicable to thyroid cancer are fluorine-18 (18F; half-life $110 \mathrm{~min}-$ utes) and iodine-124 (124I; half-life 4.2 days). Using these radioisotopes; $18 \mathrm{~F}$-flourodeoxyglucose, sodium ${ }^{18}$ F-fluoride, ${ }^{18} \mathrm{~F}$-dihyroxyphenylalanine (18F-DOPA), and 124 I have each been used in thyroid cancer imaging to varying degrees.

Positrons originate when a proton rich nucleus of an unstable parent compound decays, converting the proton to a neutron and emitting a positron (a positively charged electron) and a neutrino out of the nucleus. The positron travels a short distance until it combines with an electron and is annihilated. This annihilation event always produces two "anti-parallel" $511 \mathrm{keV}$ photons, so named because they travel in exactly opposite directions from each other along a straight line known as the "line of response". The nearly simultaneous, or "coincidental", interaction of these photons with the ring of detectors in the PET scanner can be identified by electronic circuitry. The registration of the desired coincidental signals is known as a "true coincidence" event. An erroneous "scattered coincidence" occurs if one or both of the photons is scattered, which results in their lines of travel no longer being anti-parallel. Connecting a line between their points of impact with the detectors creates a false line of response. An erroneous "random coincidence" occurs when more than 2 photons from separate annihilation events impact the detectors coincidentally so that it is difficult to tell which photon pairs were anti-parallel. If a line of response is drawn between two random photon impacts an error is generated.

The processes involved in detecting true events, correcting for scattered and random events, and correction for tissue attenuation are highly complicated. Costs rise dramatically with increasingly advanced technology to address these problems. At the lower end of this technology is traditional nuclear medicine single photon emission computed tomography (SPECT) equipment configured with ultra-high energy collimators, and modified systems that replace the traditional multi-head crystals and collimators with multi-head coincidence imaging circuitry and PET detectors operated on the same conventional gantry. These systems may cost \$0.6-0.8 million US dollars, and yield the best results in low attenuation tissues like lung and are less sensitive for smaller lesions $(<15$ $\mathrm{mm})$. Despite some favorable support for these nondedicated PET systems in thyroid cancer $(3,4)$, they are not reimbursed by the CMS for thyroid cancer imaging (5). Instead, the CMS requires higher-end dedicated PET technology equipped with full or partial ring detectors for thyroid cancer imaging (5). These instruments typically cost \$1-2.5 million US.

\section{WHAT INFORMATION DOES A PET SCAN PROVIDE?}

PET provides a quantitative depiction of radionuclide uptake throughout the entire body by obtaining an emission scan for imaging and transmission scan, traditionally with ${ }^{68} \mathrm{Ge}$ rods, for attenuation correction. Each bed position covers an axial field of view of approximately $15-18 \mathrm{~cm}$, producing approximately 63 image planes with about $3.1 \mathrm{~mm}$ between planes $(6,7)$. Patients are most commonly imaged from the base of the skull to the mid-thigh covering $6-8$ bed positions and taking about 45-60 minutes to complete (6). The acquisition time has been reduced to approximately 20-30 minutes with the newer combined $\mathrm{PET} / \mathrm{CT}$ imaging technology. The attenuation corrected images are reconstructed using complex algorithms and are displayed in coronal, axial, and sagital planes. The data are also routinely assimilated into a 3 dimensional maximum intensity projection set of images that can be rotated by the physician as desired. 
Image resolution from a point source in a phantom is about 4-6 $\mathrm{mm}$ with the most advanced human scanners (6), while 7-9 $\mathrm{mm}$ is typical of older scanners $(8,9)$. Error in the measurement of volumes of spheres with diameters of $10 \mathrm{~mm}$ or $>13 \mathrm{~mm}$ are about $50 \%$ and $<20 \%$, respectively $(8)$. PET images can be coregistered with $\mathrm{CT}$ or $\mathrm{MR}$ images by side-by-side interpretation (the physician's own "visual fusion”), or by software or (incomplete) hardware fusion to combine functional with structural imaging to optimize lesion localization $(6,10)$. Fusion (co-registration) of images has the potential to increase the accuracy of scan interpretation by localizing disease to suspicious structures while simultaneously identifying benign causes of FDG uptake such as muscle, adipose tissue, thymus, vocal cords [with or without paralysis (11)] and arthritis. Increasingly common is the utilization of combined hardware fusion CT/PET devices that enhance and simplify this process at a single setting with greater speed (6). Palmedo et al. (12) studied DTC patients and reported the accuracy of PET, sideby-side PET and CT, and hardware fused PET/CT as $78 \%, 85 \%$, and $93 \%$, respectively. The addition of $\mathrm{PET} / \mathrm{CT}$ fusion by co-registration led to a change in therapy in $48 \%$ of patients, and futile surgery was prevented in an additional 8\%. Similarly, Zoller et al. (13) reported that $\mathrm{PET} / \mathrm{CT}$ fusion modified the final interpretation in $77 \%$, and changed the treatment plan in $23 \%$ of WBS negative, Tg positive DTC patients. With PET/CT units, the CT data may be used for attenuation correction, thus eliminating the ${ }^{68} \mathrm{Ge}$ transmission scan with superior results in a small fraction of the time. Algorithms to account for serious attenuation correction "hotspot" artifacts from CT oral contrast, metallic implants (including dental), and prostheses that specifically occur when CT data is utilized for attenuation correction are emerging, while intravenous contrast appears to cause minimal hotspot artifact problems $(6,14)$. Currently, these errors may be suspected by reviewing both the attenuation corrected and uncorrected PET images when CT-based attenuation correction is used.

The first PET/CT prototype was introduced in 1998. Today, several equipment generations later, these rapidly improving PET/CT systems account for the majority of PET image system sales. Recent developments, including 3-dimensional acquisition capabilities and lutetium oxyorthosilicate (LSO) detectors, may reduce image acquisition times to less than 10 minutes $(2,6)$. Soon, it may take longer to interpret and dictate the images than to acquire them. With most PET/CT units, images can be viewed in 3 differ- ent formats: without attenuation correction, with ${ }^{68} \mathrm{Ge}$ or CT attenuation correction and attenuation corrected images fused with CT. Despite the gains in speed and anatomic co-localization, errors have been reported in 2\% of PET/CT studies when CT is used for either attenuation correction or fusion. These errors occur mostly when true liver dome lesions are mislocalized to the right lung base likely due to respiratory motion differences between imaging methodologies (15). Future methodologies that incorporate respiratory gating may minimize these artifacts $(6,10)$. However, the total minimal theoretical error of PET/CT fusion localization may be $10 \mathrm{~mm}$ in all directions, and may be twice that in the diaphragmatic area (10). Fusion of 131 I-SPECT and CT or MR images may also offer improved lesion localization. This practice has not been widely adopted (16), however appreciation and availability of this technology may rise as a byproduct of the PET-CT fusion development. PET-CT has increased the familiarity of Nuclear Medicine Physicians with $\mathrm{CT}$ anatomic imaging and reduced the cost of SPECT-CT imaging equipment. These later units may increasingly replace traditional stand-alone SPECT equipment in Nuclear Medicine Departments.

Besides images, PET also offers quantification of radionuclide uptake, which most often is described by the standardized uptake value (SUV). SUV= mean activity within a region of interest/(decay corrected total administered activity/body weight). This quantification is useful, but not a panacea and must be interpreted in both the clinical context and the methodology limitations (17). An SUV above about 2.0-2.5 is often regarded as suspicious for malignancy, while lesions with lower values are more likely to be benign (18-20). However, elevated SUV values can also be demonstrated with some benign processes, infection, or inflammation (21). Conversely, knowing that some malignancies are slow growing and have slow rates of glucose metabolism, it is not surprising that some malignancies have SUV values below 2.0-2.5 (22). The SUV value can be followed over time to monitor response to treatment such as external beam radiation therapy, or chemotherapy. However, comparing SUV values between different reports, equipment, PET centers, and methodologies is problematic given the many influential variables including the timing of imaging after radionuclide administration; and other acquisition, reconstruction, and region-of-interest parameters. Therefore, it is important when assessing response to therapy to acquire images on the same scanner with the same dose and the same time from injection to scan. 


\section{WHAT IS FDG?}

FDG is a glucose molecule which has been altered by removing the second hydroxyl group and replacing it with the cyclotron produced radioisotope 18-fluorine $\left({ }^{18} \mathrm{~F}\right)$ to make 2-deoxy-2-[18F]fluorodeoxyglucose (FDG). After production, FDG is tested for sterility, pyrogenicity and radiochemical purity before clinical use. Patients are allowed to drink water, but otherwise are fasted for at least $4-8$ hours to minimize competitive inhibition of FDG uptake by blood glucose, and imaging typically occurs about 60-90 minutes after intravenous FDG injection $(7,9)$. Serum glucose should be less than $200 \mathrm{mg} / \mathrm{dl}$ in patients with diabetes mellitus and insulin should not be administered within 2 hours of the FDG injection (7). Both glucose and FDG are transported from the vasculature into cells by glucose transporters (Glut), and are then phosphorylated by hexokinase. A glucose molecule is then converted to fructose, then to pyruvate, and then finally enters into the citric acid cycle or is metabolized by anaerobic respiration. Differently, the phosphorylated FDG molecule (18FDG-6-phosphate) cannot be further metabolized and accumulates in the cell in proportion to glucose utilization, allowing for PET imaging of hypermetabolic tissues.

Normal tissues that significantly accumulate FDG include the brain and heart, with moderate uptake in the liver, the mediastinum, and large vessels. FDG that is not accumulated intracellularly is excreted by the kidneys and is seen in the bladder and renal collecting system. Active muscles readily accumulate FDG. Efforts should be made to prevent shivering, chewing, or speaking in order to avoid increased neck uptake or vocal cord activity, which may be mistaken for disease.

\section{FDG-PET THYROID INCIDENTALOMAS}

As with all previous imaging advancements, “incidentalomas" of endocrine organs are being identified, including those of the thyroid. Focal FDG-PET thyroid incidentalomas are now identified in $\sim 2 \%$ of patients and, notably, about one-third of those with histological diagnoses have proven to be thyroid cancer (table 1) (23-26). Only speculation exists as to why so many incidental thyroid carcinomas are FDG-avid, and yet the minority of DTC patients with metastatic disease are FDG-avid unless the serum $\mathrm{Tg}$ is significantly elevated. Perhaps this is related to the volume of the individual lesions. Some have reported that the maximum SUV of incidental thyroid hypermetabolic foci did not differentiate between benign and malignant lesions $(24,27,28)$, while others have found the SUV to be helpful $(26,29)$. Diffuse thyroid uptake, as opposed to focal uptake, was reported by Kim et al. in 1.1\% of oncology patients who underwent FDG-PET imaging (24). This finding is most often associated with autoimmune thyroid disease, or a normal variant $(24,30)$.

\section{FDG-PET IN THYROID NODULES}

Most non-toxic thyroid nodules are benign, and are best evaluated with a fine-needle aspiration biopsy which is diagnostic in the majority of cases and highly accurate (31). However, up to $20 \%$ of cases are inconclusive, such as when there is suspicion of a follicular neoplasm. Currently, most of these cases require surgery to exclude carcinoma, which is present in less than $20 \%$ of cases. While investigational molecular diagnostic testing to better characterize these lesions is promising, these methodologies are not currently

Table 1. Thyroid incidentalomas with FDG-PET.

\begin{tabular}{|c|c|c|c|c|}
\hline Reference & $\begin{array}{c}\text { \# of } \\
\text { subjects }\end{array}$ & Study indication & $\begin{array}{c}\% \text { of subjects with } \\
\text { focal thyroid } \\
\text { lesions }\end{array}$ & $\begin{array}{l}\% \text { of focal thyroid } \\
\text { lesions proven } \\
\text { malignant }\end{array}$ \\
\hline 25 & 1,912 & Other cancer & $1.5 \%$ & $50 \%$ \\
\hline 24 & 4,136 & Other cancer & $1.1 \%$ & $50 \%$ \\
\hline 26 & 4,803 & Healthy screening & $1.2 \%$ & $14 \%$ \\
\hline 23 & 1,330 & $\begin{array}{c}\text { Other cancer \& } \\
\text { healthy screening }\end{array}$ & $2.2 \%$ & $27 \%$ \\
\hline 29 & 1763 & $\begin{array}{c}\text { Other cancer \& } \\
\text { healthy screening }\end{array}$ & $4.0 \%$ & $37 \%$ \\
\hline 28 & 140 & Lung cancer & $4.3 \%$ & $57 \%$ \\
\hline AVERAGE & & & $2.4 \%$ & $39 \%$ \\
\hline
\end{tabular}


available (32). Geus-Oei et al. studied 44 consecutive patients with inclusive FNA results with FDG-PET who then underwent surgery (33). Interestingly, all 6 patients with DTC had a positive pre-operative FDGPET scan, compared to only 13 of the 38 patients with benign pathology. The SUV value was not helpful towards distinguishing benign from malignant pathology. These authors propose that if surgery were done only on patients with inconclusive cytology and a positive PET scan, then unnecessary surgery would be reduced by $66 \%$. The value of this approach depends critically on a high negative predictive value of the FDG-PET scan. Unfortunately, Mitchell et al. (34) reported that only 9 of 15 thyroid carcinomas were FDG-PET positive (sensitivity 60\%), while 30 of 33 benign lesions were FDG-PET negative (specificity $91 \%$ ), for an overall negative predictive value of only 83\%. Most recently, Kim et al. (35) investigated 46 follicular neoplasms with FDG-PET. All lesions were PET positive compared to normal thyroid tissue while 21 of the 36 operated lesions were benign and SUV $V_{\max }$ did not differentiate benign from malignant nodules. The authors concluded that FDG-PET was of limited value in selecting patients for surgery.

\section{FDG-PET IN THYROID CANCER}

Since the first positive report of FDG-PET in thyroid cancer, in 1987 (36), a number of specific potential uses of PET have been considered in thyroidology (table 2). To date, the greatest attention has been paid to DTC patients that are WBS negative and Tg positive. A combination of developments has contributed to the currently rising interest in FDG-PET for thyroid carcinoma imaging. First, improved thyroglobulin assays have made it clear that a substantial fraction of DTC patients have residual disease after initial surgery and radioiodine administration (37). In the past, with less robust assays, these patients were typically considered free of disease only to demonstrate disease recurrence years or even decades later (37). Second, it has become equally clear that the majority of patients with persistent disease have negative diagnostic radioiodine WBS $(38,39)$. Third, it has been demonstrated that thyroid carcinomas with low iodine avidity tend to have higher glucose metabolism and are more likely positive on FDG-PET scans (a marker of tumor dedifferentiation), while those tumors that concentrate radioiodine well are unlikely to yield positive FDGPET scans (40). When used together, radioiodine imaging and FDG-PET were reportedly $95 \%$ sensitivi- ty for the detection of residual DTC (40), although this may be an overestimate. Fourth, greater attention has been paid to thyroid cancer mortality, in part because it has the highest mortality of the traditional endocrine tumors (despite the fairly small total number of annual deaths), and because new pharmaceuticals are being developed that preliminarily demonstrate promise in treating these tumors which have proven refractory to traditional chemotherapy. Because of this, attempts to identify patients at highest risk of death and to localize their disease with FDGPET have been made. Consistent with FDG uptake being a marker of more aggressive tumor dedifferentiation, Wang et al., from the Memorial Sloan Kettering Cancer Center (MSKCC), found the 3-year survival of patients with FDG-avid tumor metastases volumes of $125 \mathrm{~mL}$ or less was $96 \%$ compared to $18 \%$ in patients with FDG tumor volumes greater than $125 \mathrm{~mL}$ (41). Similarly, Pryma et al. (42) have reported that each increase in intensity by $\mathrm{SUV}_{\max }$ unit was associated with a $6 \%$ increase in mortality among patients with Hürthle cell carcinoma (HTC). The 5-year overall survival in patients with $\mathrm{SUV}_{\max }<10$ was $92 \%$, whereas it declined to $64 \%$ in those with $\mathrm{SUV}_{\max }>10$. Most recently, the MSKCC group expanded their series to include 400 thyroid cancer patients who underwent FDG-PET imaging (43). Multivariate analysis included age at imaging, AJCC stage, histopathology, gender, serum Tg during TSH suppression, radioiodine

Table 2. Potential indications for PET scanning in thyroid cancer. [Adapted from Larson and Robbins (82)]

\section{Strongest Indications for PET Imaging \\ Thyroglobulin positive with unknown tumor location. High-risk patients to determine the extent of disease (including those with known metastatic disease who may have additional metastases). \\ To determine long-term prognosis. \\ Post-treatment response assessment. \\ Hürthle cell carcinoma evaluation and management $(42,49,50)$. \\ Selection of patients with aggressive distant metastases for experimental therapies.}

Weaker Indications for PET Imaging
Low-risk patients to determine extent of disease.
Known metastases to determine their extent and relation-
ship to vital structures.
Lesional dosimetry (124I; half-life $\sim 4$ days) allowing both
scatter and attenuation correction $(83,84)$.
Evaluation of the thyroid nodule [table 1 and reference 85$]$.
Evaluation of thyroid nodules with inconclusive FNA cytol-
ogy $(33,35)$.


avidity, FDG avidity, number of FDG avid lesions, and site of metastases. The results indicated that only age, FDG avidity, number of FDG lesions, and SUV $\mathrm{Tax}_{\text {max }}$ were significant predictors of survival. The median survival for FDG-positive patients was 53 months after the PET scan, compared to only 2 deaths from the 180 FDG-negative patients. Finally, PET imaging is increasingly available to referring physicians, and the United States Centers of Medicare \& Medicaid Services (CMS) has recently relaxed FDG-PET reimbursement restrictions for imaging of DTC patients and private insurance companies have increasingly provided coverage as well.

\section{HOW ACCURATE IS FDG-PET IMAGING IN PATIENTS WITH THYROID CARCINOMA?}

A number of alternative radiopharmaceuticals have been tried to identify DTC metastases, especially when radioiodine fails. These radiopharmaceuticals have included 201Tl, 99m Tc-sestamibi, 99mTc-tetrofosmin, $99 \mathrm{mTc}$-depreotide, and ${ }^{111} \mathrm{In}$-octreotide which, at times, have been uniquely helpful (44). However, these alternative imaging agents have typically been less useful than FDG $(45,46)$. The same was true when FDG was compared to $99 \mathrm{mTc}$-methylene diphosphonate bone scintigraphy for osseous metastases (47).

Hooft et al. (48) performed a systematic review of the PET literature in papillary (PTC) or follicular thyroid cancer (FTC). Fourteen studies met criteria for study inclusion, and all claimed a beneficial role for FDG-PET but at evidence levels of 3 or 4 with 4 being the lowest quality. They reported considerable methodological problems in the studies and $50 \%$ of the criteria to establish internal validity were not met. FDG-PET sensitivity was reported as 70-95\%, and specificity as $77-100 \%$, although it was suspected that these were overestimated. An additional literature review reported the median sensitivity and specificity as $77 \%$ and $78 \%$, respectively (7), although FDG-PET may be more robust for HTC as opposed to PTC and FTC $(42,49,50)$. Hooft et al. concluded their 2001 report by stating that studies supported the use of FDG-PET to find foci of disease in ${ }^{131} \mathrm{I}$ WBS negative, $\mathrm{Tg}$ positive patients, but that the implementation of FDG-PET into a routine algorithm required additional evidence (48).

Nahas et al. evaluated 33 DTC patients with suspected recurrent DTC using PET/CT. PET/CT sensitivity was $66 \%$, and altered the treatment plan in $40 \%$ (51). Outcome data of operated patients were not reported. Studies such as this are encouraging as they demonstrate reasonable tumor detection accuracy and a contribution to treatment planning. However, most available studies provide little conclusive information to decide if the patient's long-term morbidity or mortality is really changed by the FDG-PET findings. The number of patients cured of disease because of the FDGPET scan is typically not clearly reported, but is likely to be low if stringent criteria are used to declare patients free of disease. Finally, for those patients potentially rendered free of disease, it is often unclear if this outcome could have been achieved with more cost-effective modalities such as neck US and chest CT.

\section{FDG-PET SCANS ARE MORE LIKELY TO BE POSITIVE WHEN THE THYROGLOBULIN VALUE IS HIGH}

Schlüter et al. (52) performed 118 FDG-PET scans in 64 patients of whom 48 had WBS negative, $\mathrm{Tg}$ positive disease. True positive studies were found in $11 \%, 50 \%$, $80 \%, 63 \%$, and $93 \%$ of those with $\mathrm{Tg}<10,10-20$, 20-50, 50-100, and > $100 \mathrm{ng} / \mathrm{ml}$, respectively (with or without TSH stimulation) (figure 1). Zimmer et al. (53) reported that their patients with positive FDGPET scans had an average $\mathrm{Tg}$ of $293 \mathrm{ng} / \mathrm{ml}$ (range 26-747), while those with negative scans had an average $\mathrm{Tg}$ of $30 \mathrm{ng} / \mathrm{ml}$ (range 3-44). Several additional studies also reported higher sensitivity in patients with Tg levels $>10$ or $15 \mathrm{ng} / \mathrm{ml}(3,51,54,55)$. Shammas et al. (56) also found a correlation between the rate of positive scans with PET/CT and the serum Tg with a more encouraging rate of detection at lower $\mathrm{Tg}$ levels. They reported positive $\mathrm{PET} / \mathrm{CT}$ images in $14 \%, 45 \%$, and $62 \%$ of patients with $\mathrm{Tg}$ levels less than $5,5-10$, and > $10 \mathrm{ng} / \mathrm{mL}$, respectively, which changed clinical management in $44 \%$ of patients. Collectively, however, these findings are disappointing in light of recent data suggesting that aggressive detection and surgical resection of metastatic disease can biochemically cure just over $10 \%$ of patients whose serum $\mathrm{Tg}$ is detectable during $\mathrm{TSH}$ suppression, a rate that rises to about one-third if the $\mathrm{Tg}$ is only detectable during $\mathrm{TSH}$ stimulation (AlSaif O, Farrar WB, Bloomston M, Ringel MD, Kloos RT. manuscript in preparation).

\section{FDG-PET SCANS ARE IMPROVED BY THYROID HORMONE WITHDRAWAL}

In 1993, Sisson et al. (57) reported a patient with pulmonary metastases from PTC that had greater FDG uptake during hypothyroidism compared to the uptake 


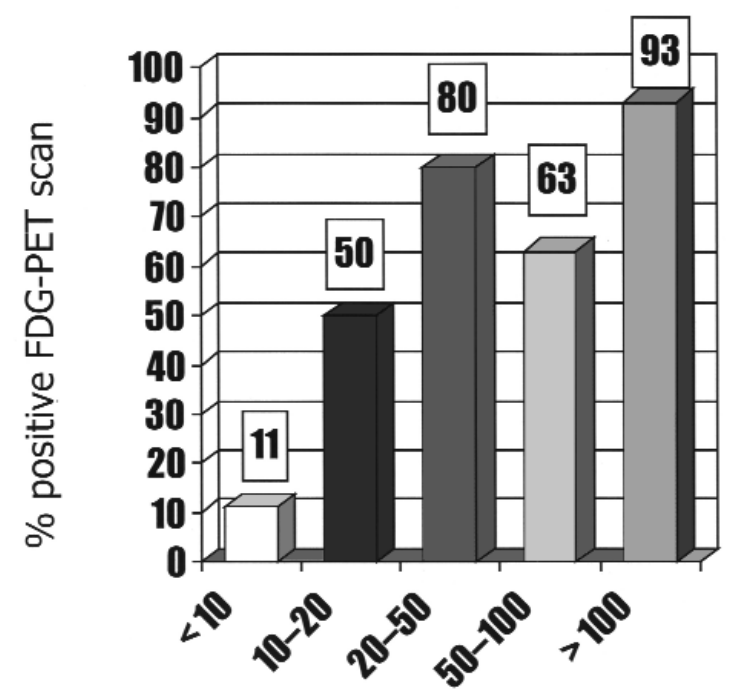

$\mathrm{Tg} \mathrm{ng} / \mathrm{ml}$

Figure 1. Thyroglobulin level correlates with FDG-PET sensitivity. Figure derived from Schlüter et al. (52).

during TSH suppression. Over the subsequent years conflicting reports have been published regarding the benefit of FDG-PET imaging during TSH stimulation with hypothyroidism. In a 2000 invited commentary, Grünwald and Biersack (58) concluded that "taking all these reports together, a clear recommendation concerning thyroid hormone medication before FDG-PET is not yet possible." The following year, Hooft et al. (48) concluded from their systematic review of the literature regarding thyroxine withdrawal for FDG-PET imaging that "the present data are confusing".

In 2002, Van Tol et al. (59) reported 8 patients studied sequentially first during TSH suppression and then during hypothyroidism with mean TSH levels of $0.04 \mathrm{mU} / \mathrm{L}$ and $64 \mathrm{mU} / \mathrm{L}$, respectively. FDG-PET images were abnormal in 4 patients during TSH suppression, abnormal in 5 patients during hypothyroidism, and more lesions were identified in 2 patients during TSH stimulation. All patients demonstrated better lesion-to-background contrast during thyroxine withdrawal which probably resulted from both increased lesion uptake from TSH stimulation, and decreased background uptake from hypothyroidism (60). The authors reported that clinical management was changed in 2 patients based on the TSH stimulated PET scan findings. Alzahrani et al. (61) studied 50 non-selected DTC patients with FDG-PET during hypothyroidism and reported sensitivity, specificity, and positive and negative predictive values of $62 \%$,
$88 \%, 96 \%$, and 30\%, respectively. Taken together, these studies suggest a possible modest benefit to TSH stimulated, as opposed to TSH suppressed, FDG-PET scans to optimize imaging sensitivity which may be most relevant when the baseline serum $\mathrm{Tg}$ is low.

\section{FDG-PET SCANS ARE IMPROVED BY SIMULTA NEOUS TSH STIMULATION AND THYROXINE THERAPY}

Several glucose transporters (Glut) have been described that move glucose into cells. Glutl is expressed in aggressive thyroid carcinomas (62-65). TSH stimulation increases glucose metabolism in thyroid cells, and increases Glutl expression (66-70). Triiodothyronine and levothyroxine may increase both Glutl and Glut4 expression (71-73). These findings suggest that recombinant human TSH (rhTSH, Thyrogen ${ }^{\circledR}$ ) may offer the unique opportunity to take advantage of both mechanisms by continuing exogenous thyroid hormone replacement/ suppression and simultaneously providing TSH stimulation.

Petrich et al. (74) investigated 30 patients with FDG-PET during TSH suppression and again after rhTSH. During TSH suppression, PET scans were positive in $30 \%$ with identification of 22 tumor-like foci. After rhTSH, 63\% had positive PET scans with 78 tumor-like foci identified ( 15 of these 78 foci were subsequently confirmed as tumor). The tumor-to-background ratio (TBR) was increased from 2.5 to $5.5(\mathrm{P}<$ 0.0001 ) after rhTSH. Similarly, the SUV increased from 2.1 to $2.8(\mathrm{P}<0.001)$ with rhTSH. Conversely, 4 inflammatory lymph nodes had a TBR of 2.0 and an SUV of 1.1 that did not significantly increase with rhTSH. Based on the 15 surgically confirmed lesions, FDG-PET sensitivity was 53\% during TSH suppression and $87 \%$ during rhTSH stimulation. The authors felt that the rhTSH stimulated FDG-PET scan suggested a specific therapeutic intervention in 17 patients $(57 \%)$, with surgery being indicated in 7 (23\%).

Chin et al. studied 7 patients with 131I DxWBS negative, Tg positive DTC with FDG-PET combined with in-line PET-helical CT fusion during TSH suppression and after rhTSH stimulation in a prospective randomized study (9). Three patients had negative FDG-PET scans. Three patients had 5 lesions identified on TSH suppressed PET scans and all of these lesions were seen on the rhTSH-stimulated PET scans. Four lesions were seen only on the rhTSH-stimulated PET scans, including 1 patient who was only positive on the rhTSH- stimulated PET scan that revealed 3 foci. The maximum lesion to background ratio was 1.7 
and 2.5 during TSH suppression and rhTSH stimulation, respectively $(\mathrm{P}=0.02)$. Similarly, the mean SUV was 1.8 and 2.0 during TSH suppression and rhTSH stimulation, respectively $(\mathrm{P}=0.06)$. These data suggest a possible modest benefit to rhTSH-stimulated FDGPET imaging, as opposed to TSH suppressed FDGPET imaging, by optimizing scan sensitivity. Importantly, no studies have directly compared the utility of FDG-PET scans after rhTSH to those stimulated by thyroid hormone withdrawal.

\section{CENTERS FOR MEDICARE \& MEDICAID SERVICES (CMS) AND FDG-PET FOR THYROID CANCER}

The CMS considered and denied FDG-PET coverage for thyroid cancer on December 15, 2000 (\#CAG00095N <http://www.cms.gov/mcd>). As a result, the American Thyroid Association, in cooperation with The Endocrine Society and the American Association of Clinical Endocrinologists (AACE), requested the issue be revisited and outlined specific patients scenarios to be considered.

Under the direction of the CMS, the Agency for Healthcare Research and Quality performed a technology assessment. A literature search yielded 1,392 citations, of which 41 considered FDG-PET and treated thyroid cancer. Twenty-two were eliminated for inadequate sample size. Of the remaining 19 studies, only 2 were prospective studies that included only WBS negative, Tg positive subjects. Only 1 of these studies allowed a reliable estimate of test performance. The CMS additionally reviewed the AACE/American Association of Endocrine Surgeons (AAES) thyroid cancer guidelines, and expert opinion was heard.

In regards to FDG-PET for WBS negative, $\mathrm{Tg}$ positive patients the CMS was unable to find sufficient studies to define diagnostic characteristics of FDGPET. Studies of FDG-PET altering clinical management were not optimal, but trended toward modifying therapy, and a few studies reported disease cure. The guidelines reviewed did not critically appraise the evidence, but supported FDG-PET in this setting, as did the expert opinions. Resultantly, and effective October 1,2003 , the CMS expanded is coverage to include FDG-PET for WBS negative, Tg positive DTC patients under very specific circumstances that included prior thyroidectomy and radioiodine ablation with a serum thyroglobulin $>10 \mathrm{ng} / \mathrm{ml}$ and negative $131 \mathrm{I}$ whole body scan. The CMS considered and denied coverage for 1) initial staging post-operatively of thy- roid cancers known to concentrate 131I poorly, 2) medullary thyroid cancer with an elevated calcitonin and negative standard imaging, and 3 ) the identification of patients with metastatic thyroid cancer at highest risk of death over the following 3 years (41).

In 2005, the CMS eased the restrictions on PET for a variety of tumors, and announced a new initiative to provide reimbursement for PET when patients and physicians participate in high-quality clinical studies or submit information to a National Oncologic PET Registry (NOPR). Referring physicians submit surveys to the database both before and after the PET scan. Now, all thyroid cancer patients (including MTC) that do not currently qualify for approved CMS PET coverage can undergo FDG-PET imaging under the NOPR program for diagnosis, initial staging, treatment monitoring or for restaging/suspected recurrence. The goal of NOPR is to evaluate the effectiveness of PET for a variety of indications and to determine if PET has any effect on clinical decisions.

\section{FDG-PET THYROID CANCER IMAGING CAVEATS}

Three FDG-PET caveats for thyroid carcinoma are listed in table 3 . The clinician must consider what the goal of the PET scan is, or its potential impact on the patient. FDG-PET findings (besides resectable local disease) that would alter management include lesions that may benefit from surgical stabilization, external beam radiation, radiofrequency ablation, ethanol injection, and/or chemo-embolization. Further, identification of distant metastatic disease on FDG-PET imaging may abrogate the need/benefit of surgical resection of local disease and, therefore, change patient management. Additionally, a lesion may be identified that requires no immediate intervention but the finding does impact their follow-up management (such as a newly localized small vertebral metastasis that would be followed by periodic CT examinations). However, for most patients, the optimal goal of FDGPET imaging is to identify surgically resectable lesions to render the patient free of disease. Therefore, the

Table 3. FDG-PET imaging caveats for thyroid carcinoma.

Get a neck and superior mediastinal neck ultrasound by a skilled observer before getting a PET scan. Get a thin cut helical chest CT before getting a PET scan. Beware of false positive FDG-PET foci. Confirm the lesion by a second modality if management is dependent upon the result. 
first FDG-PET caveat is that careful imaging of the neck should be performed before obtaining an FDGPET scan. Regional lymph nodes are the most common and most treatable site of PTC metastasis. For most medical centers, the most sensitive test for local lymph node metastases is skilled ultrasonography (US) of the neck to include the central compartment, the lateral compartments and the superior mediastinum. Neck ultrasound, in the hands of a skilled ultrasonographer, has the potential to identify malignant lymph nodes as small as 3-4 $\mathrm{mm}$ while lymph nodes in the 5-7 $\mathrm{mm}$ range are more easily found. Comparatively, the sensitivity of FDG-PET in clinical applications is typically limited to nodes with a cross sectional diameter of $8-9 \mathrm{~mm}(8,9)$ and would be expected to miss small lesions. Jeong et al. investigated the role of US, $\mathrm{CT}$, and $\mathrm{PET} / \mathrm{CT}$ in the initial evaluation of cervical lymph nodes in PTC patients, and found no additional benefit of PET/CT (75). The need for attention to neck US is seen in a study of 37 thyroid cancer patients with negative post-treatment WBS who were Tg positive (76). Of those with negative conventional images, 19 had positive FDG-PET scans (70\%) with 16 of these 19 patients having disease in the neck (14) or mediastinum (2). Another example of the need for attention to the neck is a study of 11 patients with negative post-treatment whole body scans and Tg positive disease. All patients received neck US, and neck and chest CT. FDG-PET imaging was performed and all patients had abnormal neck or mediastinal uptake which led to repeat neck US with or without biopsy, the results of which directed patient management. In both of these studies, it is unknown why these lesions were not seen on the initial neck US (which could be due to lack of expertise in the setting of thyroid cancer) or if the FDG-PET scan was truly instrumental toward identifying a small area of the body to subsequently scrutinize with repeated anatomical imaging. To put the costs of US or PET algorithms into perspective, consider that in 2003 the CMS paid $\$ 79$ for neck US ( $\$ 28$ professional fee and \$51 technical fee), compared to $\sim \$ 1,850$ for FDG-PET imaging ( $\sim 77$ professional fee, $\sim \$ 325$ for FDG, $\sim \$ 1,450$ technical fee).

The second FDG-PET caveat is that a helical thin cut chest CT should be obtained before an FDG-PET scan. With the new generation combined PET/CT scanners it is possible to accomplish these simultaneously. However, there are several reasons to obtain the chest CT before the PET scan. First, if the neck US is positive and the chest CT is negative, then these patients may be referred to surgery without the cost of a PET scan if additional metastases are not suspected based on the serum $\mathrm{Tg}$ and the clinical context. Second, if pulmonary metastases are present, then plans for radioiodine therapy (including dosimetry and/or hospitalization) can be made in the event that the PET scan is negative and radioiodine therapy is given. Third, the CT equipment and imaging methodology (including slice thickness) may not be equivalent to the equipment used for dedicated CT imaging. Finally, PET/CT images are frequently interpreted by specialists who focus on the PET findings while the CT images provide correlation. Ideally, the chest CT findings need to be carefully interpreted in their entirety and reported by a skilled physician, regardless of the PET findings. It is clear that pulmonary metastases are the most common distant site of DTC metastasis. Pulmonary metastases in the $1-3 \mathrm{~mm}$ range are commonly identified on CT, and FDG-PET has decreased sensitivity for this miliary pulmonary disease $(12,77,78)$. Indeed, one study of pulmonary metastases from various malignancies reported the sensitivity of FDG-PET for lesions < $5 \mathrm{~mm}, 5-7 \mathrm{~mm}, 8-10 \mathrm{~mm}$, and $11-28 \mathrm{~mm}$ as $0 \%, 41 \%, 78 \%$, and $94 \%$, respectively (79).

The third FDG-PET caveat is to be on guard for false-positive PET foci and to consider confirming the etiology of suspected lesions by another modality if patient management is dependent on the result. Schlüter et al. reported false positive foci in 11\% of patients, 2 of whom underwent surgery that did not yield tumor (52). Helal et al. reported that $13 \%$ of their WBS negative, Tg and FDG-PET "positive" patients had only inflamed lymph nodes at surgery (76). Similarly, Zimmer et al. reported that $25 \%$ of suspicious FDG-PET lesions were pathologically benign (53). Quantification of SUVs is modestly helpful with the higher values more likely to be malignant, however, overlap clearly remains. For example, in the Zimmer et al. patients, positive lesions had mean SUVs of $6.1 \pm 2.8$, whereas false positive lesions had SUVs of $3.9 \pm$ 1.6. The increasingly available PET/CT fusion units appear to improve diagnostic accuracy and their use is strongly preferred over standalone PET units. However, these units have not completely eliminated false positive results.

\section{DO FDG-PET SCANS HELP PATIENTS WITH METASTATIC THYROID CANCER?}

It is not clear from the literature exactly what fraction of patients with metastatic DTC is truly benefited from FDG-PET scan findings in terms of decreased morbidity, recurrence, or mortality. Contrary to the initially more optimistic reports, it appears that about one quar- 
ter of all WBS negative, $\mathrm{Tg}$ positive patients are also FDG-PET negative $(7,48)$. Patients with distant metastatic disease that is imaged by FDG-PET may have tumor that is unresponsive to current therapy so that the impact of disease identification is diminished. For patients in published studies with disease identified for whom there is an intervention, follow-up serum $\mathrm{Tg}$ data are frequently lacking or not confirmed with stimulation testing when undetectable. Thus, they may still have residual disease. Further, many patients in the literature with PET positive disease have tumor that is concurrently seen (or should have been seen) on less expensive and more readily available imaging modalities such as neck US and chest CT. Complicating these issues is the fact that many patients with metastases have some tumor deposits substantially smaller than the resolution of PET, which at its best is approximately $4-5 \mathrm{~mm}$ on the newer high resolution systems. Thus, these patients may undergo attempted curative surgery to remove disease found with FDG-PET, but still have disease postoperatively. Unfortunately, this has been the experience in the majority of patients at our medical center (unpublished data). Similarly, patients may have a mixed population of metastatic lesions, some of which are FDG avid while others are not. An example of these difficulties is the patient reported by Chin et al. who had 2 foci of disease identified on FDG-PET and co-registered with helical CT, while 3 foci where seen on a similar study after rhTSH stimulation. These 3 foci prompted cervi$\mathrm{cal}$ and mediastinal explorations that removed 19 lymph nodes of which 9 were malignant. A subsequent rhTSH-stimulated serum $\mathrm{Tg}$ rose to $1.0 \mathrm{ng} / \mathrm{dl}$. While these interventions were certainly reasonable and probably beneficial, it is clear that not all of this patient's dis-

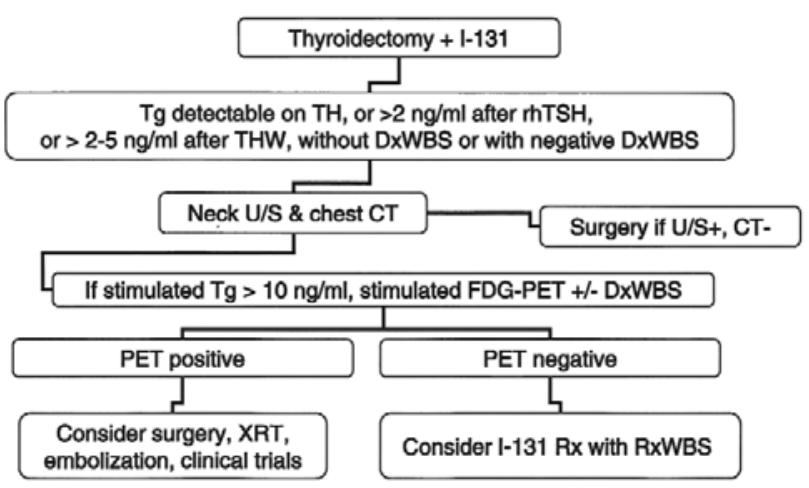

Figure 2. Potential FDG-PET algorithm for clinical practice. Thyroid hormone (TH), thyroid hormone withdrawal (THW), diagnostic whole body scan (DxWBS), post-treatment whole body scan (RxWBS), external beam radiation therapy (XRT). ease were identified by FDG-PET and, despite substantial tumor debulking, it is likely that this patient has some residual disease and whether or not their longterm outcome has been improved by these procedures is speculative.

These hesitations aside, there appear to be patients truly benefited by the use of FDG-PET (80). Figure 2 presents an algorithm for the use of FDGPET in thyroid carcinoma. Because of the probable benefit of stimulated FDG-PET scans, it is increasingly common to perform the PET scan concurrently with the WBS in patients with residual disease after the neck imaging and chest CT are found to be negative or if suspicion remains that these studies have not identified the entire residual tumor burden (figures 3 and 4 for stimulated FDG-PET protocols).

\section{FDG RADIO-GUIDED SURGERY}

Kraeber-Bodere et al. have reported FDG radio-guided surgery to assist in tumor localization in radioiodine-negative DTC, FDG-PET positive patients (81). All FDG-PET visually identified lesions were detected with the gamma probe, and the mean tumor activity was $40 \%$ higher than the surrounding neck tissue. Additional studies will be necessary to clarify the ability of radio-guided surgery to render patients free of disease, or reduce local tumor recurrence.

\section{CONCLUSIONS}

PET is a rapidly developing/evolving imaging modality that has gained widespread acceptance in oncology, with

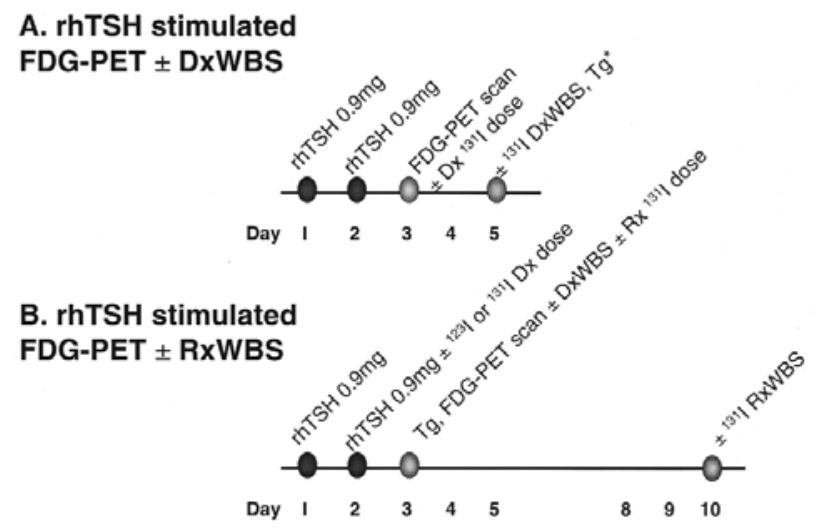

Figure 3. rhTSH stimulated FDG-PET protocol with optional diagnostic testing only (panel A) or 131| therapy (panel B). * Obtain serum Tg on day 3 if DxWBS is not obtained. Diagnostic whole body scan (DxWBS), post-treatment whole body scan (RxWBS), diagnostic (Dx), treatment $(R x)$. 


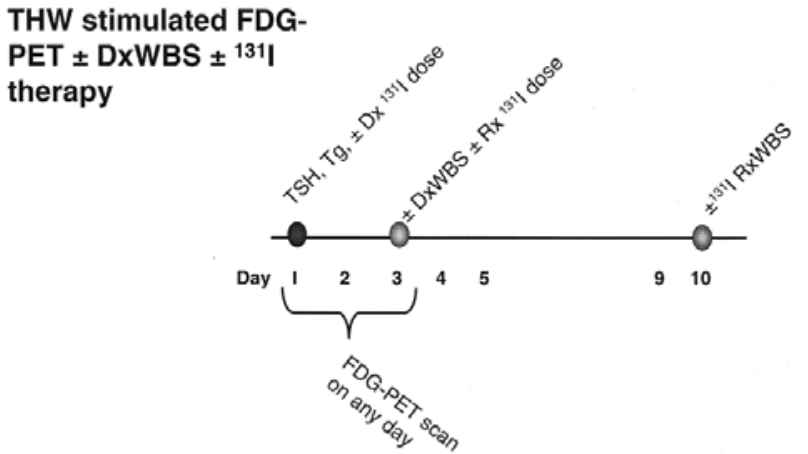

Figure 4. Hypothyroid FDG-PET protocol with optional DxWBS and 131| therapy. Diagnostic whole body scan (DxWBS), post-treatment whole body scan (RxWBS), diagnostic (Dx), treatment $(R x)$.

several radionuclides applicable to thyroid cancer currently available. Patients with thyroid disease have been studied most commonly with FDG-PET, with the greatest benefits identified so far being the potential localization of tumor in patients that are radioiodine WBS negative and $\mathrm{Tg}$ positive, the identification of patients unlikely to benefit from additional ${ }^{131}$ I therapy, and as a prognostic tool to identify patients at highest risk of disease-specific mortality which may prompt more aggressive therapy or enrollment in clinical trials. A limitation of FDG-PET is its scan resolution in the clinical setting of $\sim 5 \mathrm{~mm}$ for the highest resolution systems and just below $1 \mathrm{~cm}$ for conventional systems, which emphasizes the need to evaluate the most common sites of DTC micrometastases with more sensitive and cost-effective modalities prior to PET imaging (e.g. typically neck US and chest CT). Recent FDG-PET data have suggested greater sensitivity for disease detection when imaged with TSH stimulation (either hypothyroid or rhTSH) compared to imaging performed during TSH suppression. Finally, robust studies documenting improvements in survival or tumor recurrence in DTC populations are lacking. However, specific case examples of patients who appear to have benefited from FDG-PET imaging are available, and a role for FDG-PET in DTC management is present.

\section{ACKNOWLEDGEMENTS}

Dr. Kloos has received final support from Genzyme Corporation who manufactures Thyrogen (rhTSH) for research, speaker's honoraria, and consulting.

\section{REFERENCES}

1. Ide M. Cancer screening with FDG-PET. Q J Nucl Med Mol Imaging 2006;50:23-7.
2. Czernin J, Schelbert H. PET/CT imaging: facts, opinions, hopes, and questions. J Nucl Med 2004;45:1S-3.

3. Giammarile F, Hafdi Z, Bournaud C, Janier M, Houzard C, Desuzinges $C$, et al. Is [18F]-2-fluoro-2-deoxy-d-glucose (FDG) scintigraphy with non-dedicated positron emission tomography useful in the diagnostic management of suspected metastatic thyroid carcinoma in patients with no detectable radioiodine uptake? Eur J Endocrinol 2003;149:293-300.

4. Gonzalo IT, Itti E, Mlikotic A, Pham IH, Cesar RB, Meignan M, et al. [18F]fluorodeoxyglucose triple-head coincidence imaging as an adjunct to 131 l scanning for follow-up of papillary thyroid carcinoma. Endocr Pract 2003;9:273-9.

5. Centers of Medicare \& Medicaid Services 50-36 Positron Emission Tomography (PET or PETT). Coverage Issues Manual, 2003. Available at: <http://www.cms.hhs.gov/manuals/06 cim/ci50.asp\# 50 36>.

6. Townsend DW, Carney JPJ, Yap JT, Hall NC. PET/CT today and tomorrow. J Nucl Med 2004;45:4S-14.

7. Khan N, Oriuchi N, Higuchi T, Zhang H, Endo K. PET in the follow-up of differentiated thyroid cancer. Br J Radiol 2003;76:690-5.

8. Eschmann SM, Reischl G, Bilger K, Kupferschlager J, Thelen $\mathrm{MH}$, Dohmen BM, et al. Evaluation of dosimetry of radioiodine therapy in benign and malignant thyroid disorders by means of iodine-124 and PET. Eur J Nucl Med Mol Imaging 2002;29:760-7.

9. Chin BB, Patel P, Cohade C, Ewertz M, Wahl R, Ladenson P. Recombinant human thyrotropin stimulation of fluoro-D-glucose positron emission tomography uptake in well-differentiated thyroid carcinoma. J Clin Endocrinol Metab 2004:89:91-5.

10. Vogel WV, Oyen WJG, Barentsz JO, Kaanders JHAM, Corstens FH. PET/CT: panacea, redundancy, or something in between? J Nucl Med 2004;45:15S-24.

11. Chin BB, Patel $P$, Hammoud D. Combined positron emission tomography - computed tomography improves specificity for thyroid carcinoma by identifying vocal cord activity after laryngeal nerve paralysis. Thyroid 2003:13:1183-4.

12. Palmedo H, Bucerius J, Joe A, Strunk H, Hortling N, Meyka S, et al. Integrated PET/CT in differentiated thyroid cancer: diagnostic accuracy and impact on patient management. J Nucl Med 2006;47:616-24.

13. Zoller M, Kohlfuerst S, Igerc I, Kresnik E, Gallowitsch HJ, Gomez I, et al. Combined PET/CT in the follow-up of differentiated thyroid carcinoma: what is the impact of each modality? Eur J Nucl Med Mol Imaging 2007;34(4):487-95.

14. Nehmeh SA, Erdi YE, Kalaigian H, Kolbert KS, Pan T, Yeung $\mathrm{H}$, et al. Correction for oral contrast artifacts in CT attenuation-corrected PET images obtained by combined PET/CT. J Nucl Med 2003;44:1940-4.

15. Osman MM, Cohade $C$, Nakamoto $Y$, Marshall LT, Leal JP, Wahl RL. Clinically significant inaccurate localization of lesions with PET/CT: frequency in 300 patients. J Nucl Med 2003;44:240-3.

16. Yamamoto $Y$, Nishiyama $Y$, Monden $T$, Matsumura $Y$, Satoh K, Ohkawa M. Clinical usefulness of fusion of 131| SPECT and CT images in patients with differentiated thyroid carcinoma. J Nucl Med 2003;44:1905-10.

17. Keyes JW, Jr. SUV: standard uptake or silly useless value? J Nucl Med 1995;36:1836-9.

18. Feldman F, van Heertum R, Manos C. 18FDG PET scanning of benign and malignant musculoskeletal lesions. Skeletal Radiol 2003;32:201-8.

19. Cardona S, Schwarzbach M, Hinz U, Dimitrakopoulou-Strauss A, Attigah N, Mechtersheimer section, et al. Evaluation of ${ }^{18} \mathrm{~F}$ deoxyglucose positron emission tomography (FDG-PET) to assess the nature of neurogenic tumours. Eur J Surg Oncol 2003;29:536-41.

20. Dehdashti F, Siegel BA, Griffeth LK, Fusselman MJ, Trask DD, McGuire $A H$, et al. Benign versus malignant intraosseous lesions: discrimination by means of PET with 2-[18F]fluoro-2deoxy-D-glucose. Radiology 1996;200:243-7.

21. Aoki J, Watanabe $\mathrm{H}$, Shinozaki $\mathrm{T}$, Takagishi $\mathrm{K}$, Ishijima $\mathrm{H}, \mathrm{Oya}$ $\mathrm{N}$, et al. FDG PET of primary benign and malignant bone tumors: standardized uptake value in 52 lesions. Radiology 2001;219:774-7. 
22. Aoki J, Watanabe H, Shinozaki T, Takagishi K, Tokunaga M, Koyama $Y$, et al. FDG-PET for preoperative differential diagnosis between benign and malignant soft tissue masses. Skeletal Radiol 2003;32:133-8.

23. Kang KW, Kim SK, Kang HS, Lee ES, Sim JS, Lee IG, et al. Prevalence and risk of cancer of focal thyroid incidentaloma identified by ${ }^{18}$ F-fluorodeoxyglucose positron emission tomography for metastasis evaluation and cancer screening in healthy subjects. J Clin Endocrinol Metab 2003;88:4100-4.

24. Kim TY, Kim WB, Ryu JS, Gong G, Hong SJ, Shong YK. ${ }^{18} \mathrm{~F}-$ fluorodeoxyglucose uptake in thyroid from positron emission tomogram (PET) for evaluation in cancer patients: high prevalence of malignancy in thyroid PET incidentaloma. Laryngoscope 2005; 115:1074-8.

25. Ishimori T, Patel PV, Wahl RL. Detection of unexpected additional primary malignancies with PET/CT. J Nucl Med 2005;46:752-7

26. Chen YK, Ding HJ, Chen KT, Chen YL, Liao AC, Shen YY, et al. Prevalence and risk of cancer of focal thyroid incidentaloma identified by ${ }^{18} \mathrm{~F}$-fluorodeoxyglucose positron emission tomography for cancer screening in healthy subjects. Anticancer Res 2005;25:1421-6.

27. Are C, Hsu JF, Schoder H, Shah JP, Larson SM, Shaha AR. FDG-PET detected thyroid incidentalomas: need for further investigation? Ann Surg Oncol 2007;14:239-47.

28. Yi JG, Marom EM, Munden RF, Truong MT, Macapinlac HA, Gladish GW, et al. Focal uptake of fluorodeoxyglucose by the thyroid in patients undergoing initial disease staging with combined PET/CT for non-small cell lung cancer. Radiology 2005;236:271-5.

29. Choi JY, Lee KS, Kim HJ, Shim YM, Kwon OJ, Park K, et al. Focal thyroid lesions incidentally identified by integrated ${ }^{18} \mathrm{~F}$ FDG PET/CT: clinical significance and improved characterization. J Nucl Med 2006;47:609-15.

30. Chen YK, Chen YL, Cheng RH, Yeh CL, Lee CC, Hsu CH. The significance of FDG uptake in bilateral thyroid glands. Nucl Med Commun 2007:28:117-22.

31. Cooper DS, Doherty GM, Haugen BR, Kloos RT, Lee SL, Mandel SJ, et al. Management guidelines for patients with thyroid nodules and differentiated thyroid cancer. Thyroid 2006:16:109-41.

32. Weber F, Shen L, Aldred MA, Morrison CD, Frilling A, Saji M, et al. Genetic classification of benign and malignant thyroid follicular neoplasia based on a three-gene combination. $J$ Clin Endocrinol Metab 2005;90:2512-21.

33. Geus-Oei LF, Pieters GF, Bonenkamp JJ, Mudde AH, BleekerRovers $\mathrm{CP}$, Corstens FH, et al. ${ }^{18} \mathrm{~F}-\mathrm{FDG}$ PET reduces unnecessary hemithyroidectomies for thyroid nodules with inconclusive cytologic results. J Nucl Med 2006;47:770-5.

34. Mitchell JC, Grant F, Evenson AR, Parker JA, Hasselgren PO, Parangi S. Preoperative evaluation of thyroid nodules with 18FDG-PET/CT. Surgery 2005;138:1166-74.

35. Kim JM, Ryu JS, Kim TY, Kim WB, Kwon GY, Gong G, et al. 18F-Fluorodeoxyglucose positron emission tomography does not predict malignancy in thyroid nodules cytologically diagnosed as follicular neoplasm. J Clin Endocrinol Metab 2007:92(5):1630-4.

36. Joensuu $H$, Ahonen A. Imaging of metastases of thyroid carcinoma with fluorine-18 fluorodeoxyglucose. J Nucl Med 1987;28:910-4.

37. Mazzaferri EL, Kloos RT. Current approaches to primary therapy for papillary and follicular thyroid cancer. J Clin Endocrinol Metab 2001;86:1447-63.

38. Cailleux AF, Baudin E, Travagli JP, Ricard M, Schlumberger M. Is diagnostic iodine-131 scanning useful after total thyroid ablation for differentiated thyroid cancer? J Clin Endocrinol Metab 2000;85:175-8.

39. Mazzaferri EL, Kloos RT. Is diagnostic iodine-131 scanning with recombinant human TSH useful in the follow-up of differentiated thyroid cancer after thyroid ablation? J Clin Endocrinol Metab 2002;87:1490-8.

40. Feine U, Lietzenmayer R, Hanke JP, Held J, Wohrle H, MullerSchauenburg W. Fluorine-18-FDG and iodine-131-iodide uptake in thyroid cancer. J Nucl Med 1996;37:1468-72.
41. Wang W, Larson SM, Fazzari M, Tickoo SK, Kolbert K, Sgouros G, et al. Prognostic value of [18F]fluorodeoxyglucose positron emission tomographic scanning in patients with thyroid cancer. J Clin Endocrinol Metab 2000;85:1107-13.

42. Pryma DA, Schoder H, Gonen M, Robbins RJ, Larson SM, Yeung HW. Diagnostic accuracy and prognostic value of 18FFDG PET in Hürthle cell thyroid cancer patients. J Nucl Med 2006; $47: 1260-6$.

43. Robbins RJ, Wan Q, Grewal RK, Reibke R, Gonen M, Strauss $\mathrm{HW}$, et al. Real-time prognosis for metastatic thyroid carcinoma based on 2-[18F]fluoro-2-deoxy-D-glucose-positron emission tomography scanning. J Clin Endocrinol Metab 2006; $91: 498-505$

44. Stokkel MP, Duchateau CS, Dragoiescu C. The value of FDGPET in the follow-up of differentiated thyroid cancer: a review of the literature. $\mathbf{Q}$ J Nucl Med Mol Imaging 2006;50:78-87.

45. Grunwald F, Kalicke T, Feine U, Lietzenmayer R, Scheidhauer $\mathrm{K}$, Dietlein M, et al. Fluorine-18 fluorodeoxyglucose positron emission tomography in thyroid cancer: results of a multicentre study. Eur J Nucl Med 1999;26:1547-52.

46. Sarlis NJ, Gourgiotis L, Guthrie LC, Galen B, Skarulis MC, Shawker TH, et al. In-111 DTPA-octreotide scintigraphy for disease detection in metastatic thyroid cancer: comparison with F-18 FDG positron emission tomography and extensive conventional radiographic imaging. Clin Nucl Med 2003;28:208-17.

47. Schirrmeister H, Guhlmann A, Elsner K, Kotzerke J, Glatting $G$, Rentschler M, et al. Sensitivity in detecting osseous lesions depends on anatomic localization: planar bone scintigraphy versus 18F PET. J Nucl Med 1999;40:1623-9.

48. Hooft L, Hoekstra OS, Deville W, Lips P, Teule GJ, Boers M, et al. Diagnostic accuracy of 18F-fluorodeoxyglucose positron emission tomography in the follow-up of papillary or follicular thyroid cancer. J Clin Endocrinol Metab 2001;86:3779-86.

49. Lowe VJ, Mullan BP, Hay ID, Mclver B, Kasperbauer JL. ${ }^{18} \mathrm{~F}-$ FDG PET of patients with Hürthle cell carcinoma. J Nucl Med 2003:44:1402-6.

50. Plotkin M, Hautzel H, Krause BJ, Schmidt D, Larisch R, Mottaghy FM, et al. Implication of 2-18fluor-2-deoxyglucose positron emission tomography in the follow-up of Hürthle cell thyroid cancer. Thyroid 2002;12:155-61.

51. Nahas Z, Goldenberg D, Fakhry C, Ewertz M, Zeiger M, Ladenson PW, et al. The role of positron emission tomography/computed tomography in the management of recurrent papillary thyroid carcinoma. Laryngoscope 2005; 115:237-43.

52. Schluter B, Bohuslavizki KH, Beyer W, Plotkin M, Buchert R, Clausen M. Impact of FDG PET on patients with differentiated thyroid cancer who present with elevated thyroglobulin and negative 131| scan. J Nucl Med 2001;42:71-6.

53. Zimmer LA, McCook B, Meltzer C, Fukui M, Bascom D, Snyderman C, et al. Combined positron emission tomography/computed tomography imaging of recurrent thyroid cancer. Otolaryngol Head Neck Surg 2003; $128: 178-84$.

54. Ruiz Franco-Baux JV, Borrego D, I, Gomez CP, Rodriguez R, Jr., Vazquez Albertino RJ, Navarro GE, et al. [18F-fluordeoxyglucose positron emission tomography on patients with differentiated thyroid cancer who present elevated human serum thyroglobulin levels and negative 131| whole body scan]. Rev Esp Med Nucl 2005:24:5-13.

55. lagaru A, Masamed R, Singer PA, Conti PS. 2-Deoxy-2[18F]fluoro-D-glucose-positron emission tomography and positron emission tomography/computed tomography diagnosis of patients with recurrent papillary thyroid cancer. Mol Imaging Biol 2006;8:309-14.

56. Shammas $A$, Degirmenci $B$, Mountz JM, McCook BM, Branstetter B, Bencherif BB, et al. 18F-FDG PET/CT in patients with suspected recurrent or metastatic well-differentiated thyroid cancer. J Nucl Med 2007;48:221-6.

57. Sisson JC, Ackermann RJ, Meyer MA, Wahl RL. Uptake of 18fluoro-2-deoxy-D-glucose by thyroid cancer: implications for diagnosis and therapy. J Clin Endocrinol Metab 1993;77:1090-4. 
58. Grunwald F, Biersack HJ. FDG PET in thyroid cancer: thyroxine or not? J Nucl Med 2000;41:1996-8.

59. van Tol KM, Jager PL, Piers DA, Pruim J, de Vries EG, Dullaart $R P$, et al. Better yield of (18)fluorodeoxyglucose-positron emission tomography in patients with metastatic differentiated thyroid carcinoma during thyrotropin stimulation. Thyroid 2002;12:381-7.

60. Moog F, Linke R, Manthey N, Tiling R, Knesewitsch P, Tatsch $K$, et al. Influence of thyroid-stimulating hormone levels on uptake of FDG in recurrent and metastatic differentiated thyroid carcinoma. J Nucl Med 2000;41:1989-95.

61. Alzahrani AS, Mohamed GE, Al Rifai A, Al Sugair A, Abdel Salam SA, Sulaiman OM, et al. Role of [18F]fluorodeoxyglucose positron emission tomography in follow-up of differentiated thyroid cancer. Endocr Pract 2006;12:152-8.

62. Lazar V, Bidart JM, Caillou B, Mahé C, Lacroix L, Filetti S, et al. Expression of the $\mathrm{Na}^{+} / \mathrm{I}^{-}$symporter gene in human thyroid tumors: A comparison study with other thyroid-specific genes. J Clin Endocrinol Metab 1999;84:3228-34.

63. Samih N, Hovsepian S, Notel F, Prorok M, Zattara-Cannoni H, Mathieu S, et al. The impact of N-and O-glycosylation on the functions of Glut-1 transporter in human thyroid anaplastic cells. Biochim Biophys Acta 2003:1621:92-101.

64. Schonberger J, Ruschoff J, Grimm D, Marienhagen J, Rummele $P$, Meyringer R, et al. Glucose transporter 1 gene expression is related to thyroid neoplasms with an unfavorable prognosis: an immunohistochemical study. Thyroid 2002;12:747-54.

65. Haber RS, Weiser KR, Pritsker A, Reder I, Burstein DE. GLUT1 glucose transporter expression in benign and malignant thyroid nodules. Thyroid 1997;7:363-7.

66. Blaser D, Maschauer S, Kuwert T, Prante O. In vitro studies on the signal transduction of thyroidal uptake of $18 \mathrm{~F}-\mathrm{FDG}$ and 131|-iodide. J Nucl Med 2006;47:1382-8.

67. Filetti S, Damante G, Foti D. Thyrotropin stimulates glucose transport in cultured rat thyroid cells. Endocrinology 1987:120:2576-81.

68. Hosaka Y, Tawata M, Kurihara A, Ohtaka M, Endo T, Onaya T. The regulation of two distinct glucose transporter (GLUT1 and GLUT4) gene expressions in cultured rat thyroid cells by thyrotropin. Endocrinology 1992;131:159-65.

69. Russo D, Damante G, Foti D, Costante G, Filetti S. Different molecular mechanisms are involved in the multihormonal control of glucose transport in FRTL5 rat thyroid cells. $\mathbf{J}$ Endocrinol Invest 1994;17:323-7.

70. Samih N, Hovsepian S, Aouani A, Lombardo D, Fayet G. Glut1 translocation in FRTL-5 thyroid cells: role of phosphatidylinositol 3-kinase and N-glycosylation. Endocrinology 2000;141:4146-55.

71. Shimizu Y, Shimazu T. Thyroid hormone augments GLUT4 expression and insulin-sensitive glucose transport system in differentiating rat brown adipocytes in culture. J Vet Med Sci 2002;64:677-81.

72. Romero R, Casanova B, Pulido N, Suarez Al, Rodriguez E Rovira A. Stimulation of glucose transport by thyroid hormone in 3T3-L1 adipocytes: increased abundance of GLUT1 and GLUT4 glucose transporter proteins. J Endocrinol 2000;164:187-95.

73. Pickard MR, Sinha AK, Ogilvie LM, Leonard AJ, Edwards PR, Ekins RP. Maternal hypothyroxinemia influences glucose transporter expression in fetal brain and placenta. $J$ Endocrinol 1999;163:385-94.

74. Petrich T, Borner AR, Otto D, Hofmann M, Knapp WH. Influence of rhTSH on [18F]fluorodeoxyglucose uptake by differentiated thyroid carcinoma. Eur J Nucl Med Mol Imaging 2002;29:641-7.
75. Jeong HS, Baek CH, Son YI, Choi JY, Kim HJ, Ko YH, et al. Integrated $18 \mathrm{~F}-\mathrm{FDG}$ PET/CT for the initial evaluation of cervical node level of patients with papillary thyroid carcinoma: comparison with ultrasound and contrast-enhanced CT. Clin Endocrinol (Oxf) 2006;65:402-7.

76. Helal BO, Merlet P, Toubert ME, Franc B, Schvartz C, Gauthier-Koelesnikov $\mathrm{H}$, et al. Clinical impact of $18 \mathrm{~F}-\mathrm{FDG}$ PET in thyroid carcinoma patients with elevated thyroglobulin levels and negative ${ }^{131}$ | scanning results after therapy. J Nucl Med 2001;42:1464-9.

77. Hung MC, Wu HS, Kao CH, Chen WK, Changlai SP. ${ }^{18}$ F-fluorodeoxyglucose positron emission tomography in detecting metastatic papillary thyroid carcinoma with elevated human serum thyroglobulin levels but negative ${ }^{131}$ I whole body scan. Endocr Res 2003;29:169-75.

78. Dietlein M, Scheidhauer K, Voth E, Theissen P, Schicha H. Fluorine-18 fluorodeoxyglucose positron emission tomography and iodine-131 whole-body scintigraphy in the follow-up of differentiated thyroid cancer. Eur J Nucl Med 1997;24:1342-8.

79. Reinhardt MJ, Biermann K, Wissmeyer M, Juengling FD, Brockmann $\mathrm{H}$, von Mallek D, et al. Dose selection for radioiodine therapy of borderline hyperthyroid patients according to thyroid uptake of $99 \mathrm{mTc}$-pertechnetate: applicability to unifocal thyroid autonomy? Eur J Nucl Med Mol Imaging 2006;33:608-12.

80. Quon A, Fischbein NJ, McDougall IR, Le QT, Loo BW, Jr., Pinto $\mathrm{H}$, et al. Clinical role of ${ }^{18} \mathrm{~F}-\mathrm{FDG}$ PET/CT in the management of squamous cell carcinoma of the head and neck and thyroid carcinoma. J Nucl Med 2007:48:58S-67.

81. Kraeber-Bodere F, Cariou B, Curtet C, Bridji B, Rousseau C, Dravet $F$, et al. Feasibility and benefit of fluorine 18-fluoro-2deoxyglucose-guided surgery in the management of radioiodine-negative differentiated thyroid carcinoma metastases. Surgery 2005;138:1176-82.

82. Larson SM, Robbins R. Positron emission tomography in thyroid cancer management. Semin Roentgenol 2002;37:16974.

83. Sgouros G, Kolbert KS, Sheikh A, Pentlow KS, Mun EF, Barth $A$, et al. Patient-specific dosimetry for ${ }^{131}$ I thyroid cancer therapy using ${ }^{124}$ I PET and 3-dimensional-internal dosimetry (3DID) software. J Nucl Med 2004;45:1366-72.

84. Eschmann SM, Reischl G, Bilger K, Kupferschlager J, Thelen $\mathrm{MH}$, Dohmen BM, et al. Evaluation of dosimetry of radioiodine therapy in benign and malignant thyroid disorders by means of iodine-124 and PET. Eur J Nucl Med Mol Imaging 2002;29:760-7.

85. Kresnik E, Gallowitsch HJ, Mikosch P, Stettner H, Igerc I, Gomez I, et al. Fluorine-18-fluorodeoxyglucose positron emission tomography in the preoperative assessment of thyroid nodules in an endemic goiter area. Surgery 2003; 133:294-9.

\section{Address for correspondence:}

Richard T. Kloos

The Ohio State University

446 McCampbell Hall

1581 Dodd Drive

Columbus, OH. 43210-1296

Fax: (614) 292-1550

E-mail: richard.kloos@osumc.edu 